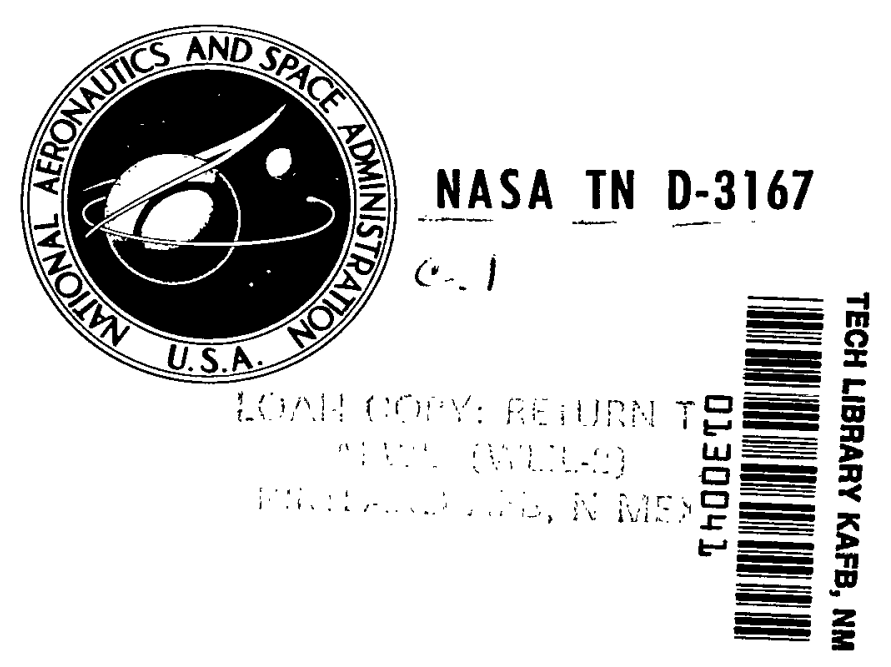

\title{
ON THE VARIATIONS OF THE THERMOSPHERIC STRUCTURE
}

by W. Priester

Goddard Space Flight Center Greenbelt, $M d$.

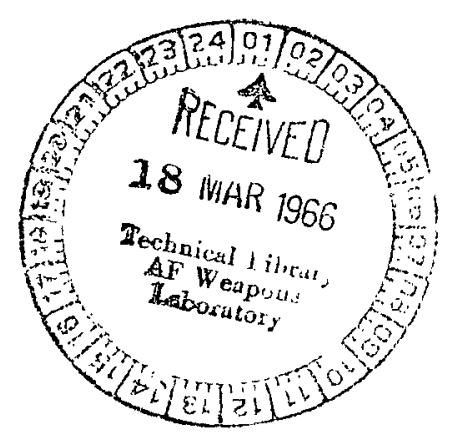

NATIONAL AERONAUTICS AND SPACE ADMINISTRATION - WASHINGTON, D. C. - MARCH 1966 
ON THE VARIATIONS OF THE THERMOSPHERIC STRUCTURE

By W. Priester

Goddard Space Flight Center

Greenbelt, Md.

\section{NATIONAL AERONAUTICS AND SPACE ADMINISTRATION}


ABSTRACT

The paper discusses the properties of the different effects which have been found to occur in the thermosphere and some conclusions which can be drawn with regard to the physics of the thermosphere.

In the discussion of the diurnal variation the emphasis is on the behavior of the diurnal amplitude in density during the solar cycle. At the height range between 200 and $300 \mathrm{~km}$ the amplitude has remarkably increased with decreasing solar activity.

The relation between atmospheric density and temperature and the solar EUV flux and the solar $10.7 \mathrm{~cm}$ flux-the latter serving as a convenient parameter-is discussed. The observational results for a phase shift between the variations in the EUV flux (or $10.7 \mathrm{~cm}$ flux) and the correlated variations in atmospheric temperature (or density) lie in the range between 0.5 and 2.3 days. During the solar minimum the atmospheric variations which parallel the $10.7 \mathrm{~cm}$ flux are far less pronounced than the variations correlated with geomagnetic activity. The phase shift derived from 45 geomagnetic storms and correlated density changes has been found to be $6 \pm 3$ (m.e.) hours. 


\section{CONTENTS}

Abstract .................... ii

INTRODUCTION $\ldots \ldots \ldots \ldots \ldots \ldots \ldots \ldots \ldots \ldots \ldots \ldots$

THE DIURNAL VARIATION .............. 1

THE 27-DAY VARIATION, THE SOLAR CYCLE EFFECT, AND THE EFFECT OF GEOMAGNETIC

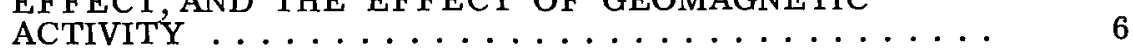

ACKNOWLEDGMENTS . . . . . . . . . . . . . . 13

References ...................... 13 


\title{
ON THE VARIATIONS OF THE THERMOSPHERIC STRUCTURE
}

\author{
by \\ W. Priester* \\ Goddard Space Flight Center
}

\section{INTRODUCTION}

The majority of the information on the time-dependent behavior of the thermosphere has been derived from satellite $\mathrm{drag}$ data which were obtained from the changes of orbital periods. These data are essentially limited to heights above $200 \mathrm{~km}$, since the lifetimes of satellites with perigees below that height are usually too short. But a few limited conclusions about the thermospheric behavior below $200 \mathrm{~km}$ can be drawn from the knowledge of the atmospheric structure and its variations above that height.

If one combines this information with the results of rocket data on density, pressure, temperature and chemical composition obtained in the lower thermosphere, one will be able to present a self-consistent picture of the entire thermosphere, except for a few discrepancies which still remain at the present time.

\section{THE DIURNAL VARIATION}

In 1959 it was found-and since then often confirmed-that the density in the height range above $200 \mathrm{~km}$ undergoes a pronounced diurnal variation with a maximum at about 1400 hours local time and a minimum at about 0400 hours. This is understood as the consequence of a diurnal temperature variation in the thermosphere which in turn is essentially caused by absorption of solar energy and downward heat conduction acting as a smoothing process.

The observations for the decreasing phase of solar activity from 1958 through 1963 have shown that the time of maximum always remains at 1400 hours local time (Reference 1) within a range of uncertainty of about \pm 1 hour. In general, the amplitude of the diurnal density variation (that is, the ratio of the density at 1400 hours to the density at 0400 hours local time) increases with height.

At any given height the amplitude is dependent on the level of solar activity within the elevenyear solar cycle. This is particularly conspicuous in the height range around $200 \mathrm{~km}$. In 1958 the

\footnotetext{
*National Academy of Sciences - National Research Council Senior Research Associate with the Goddard Institute for Space Studies; on leave from Bonn University.
} 
observations of Sputnik 3 (1958 $\delta 2$ ) yielded a diurnal amplitude of only about 10 percent at a height of $200 \mathrm{~km}$ (Reference 2). In 1963, when the level of solar activity was already close to the minimum, the orbital analysis of several satellites by King-Hele and Quinn (Reference 3) revealed a density ratio of 1.7 at $200 \mathrm{~km}$ and the results on the satellites Cosmos $1-5(1963 \theta 1,1963$ เ , $1963 \nu 1,1963 \xi 1,1963 v 1$ ) by Marov (Reference 4) suggest an even higher ratio of 1.9 at the same height. The drag data of Explorer 17 (1963.09A) (Reference 5) yielded a diurnal density ratio of 2.1 at $270 \mathrm{~km}$ for 1963 . This ratio was only 1.5 in 1958-59 as can be shown from interpolation between data from Sputnik 3 and Explorer 1 (1958 a1) (Reference 6).

The increase of the diurnal amplitude at $200 \mathrm{~km}$ with decreasing solar activity can be understood if the heating of the thermosphere depends strongly on the level of solar activity. In diffusive equilibrium the reaction of the different constituents of the atmosphere on changes of the temperature depends on their molecular weights. The summation of the partial densities of the individual constituents is what we observe from the drag measurements.

The variation of the diurnal amplitude during the solar cycle was predicted by Harris and Priester (Reference 7) in their analysis of the time-dependent behavior of the upper atmosphere. They integrated the time-dependent heat conduction equation for an atmosphere which always remains in hydrostatic equilibrium. In order to account for different levels of solar activity within the eleven year cycle, the total heat input was taken proportional to the flux of the solar $10.7 \mathrm{~cm}$ radiation which had been proved to be a useful indicator of solar activity. Later on, the measurements from the OSO 1 (1962 $\zeta 1)$ satellite on the solar EUV flux during March and April 1962 proved that there is an excellent proportionality between the EUV flux integrated from 50 to $400 \mathrm{~A}$ and the $10.7 \mathrm{~cm}$ radiation (Reference 8 ).

The analysis by Harris and Priester was based on fixed boundary conditions at a height of $120 \mathrm{~km}$. Also, for the new edition of the COSPAR International Reference Atmosphere (Reference 9) it was decided to use constant boundary conditions at $120 \mathrm{~km}$ for temperature, density and chemical composition throughout the solar cycle, since no observational evidence on a significant variation at that height is available so far.

The comparison made by King-Hele and Quinn between their observational densities for 1963 and the CIRA Model 2 corresponding to the 1963-64 level of solar activity $(\bar{F}=75)$ revealed a good agreement if the densities are averaged over 24 hours. But the diurnal amplitude of the model at $200 \mathrm{~km}$ is given by a density ratio of 1.3 instead of 1.7 as revealed by the latest observations. For heights above $240 \mathrm{~km}$, however, there is a good agreement between the model and the observations in both the average values and the diurnal amplitude. The differences between model densities and observational densities at those heights are less than 10 percent (see Figure 1).

Another slight discrepancy between the observed densities at $200 \mathrm{~km}$ and the new CIRA models occurs for times of very high solar activity (i.e. 1958). The model densities seem to be systematically too small by 10 to 15 percent (see Figure 2). 


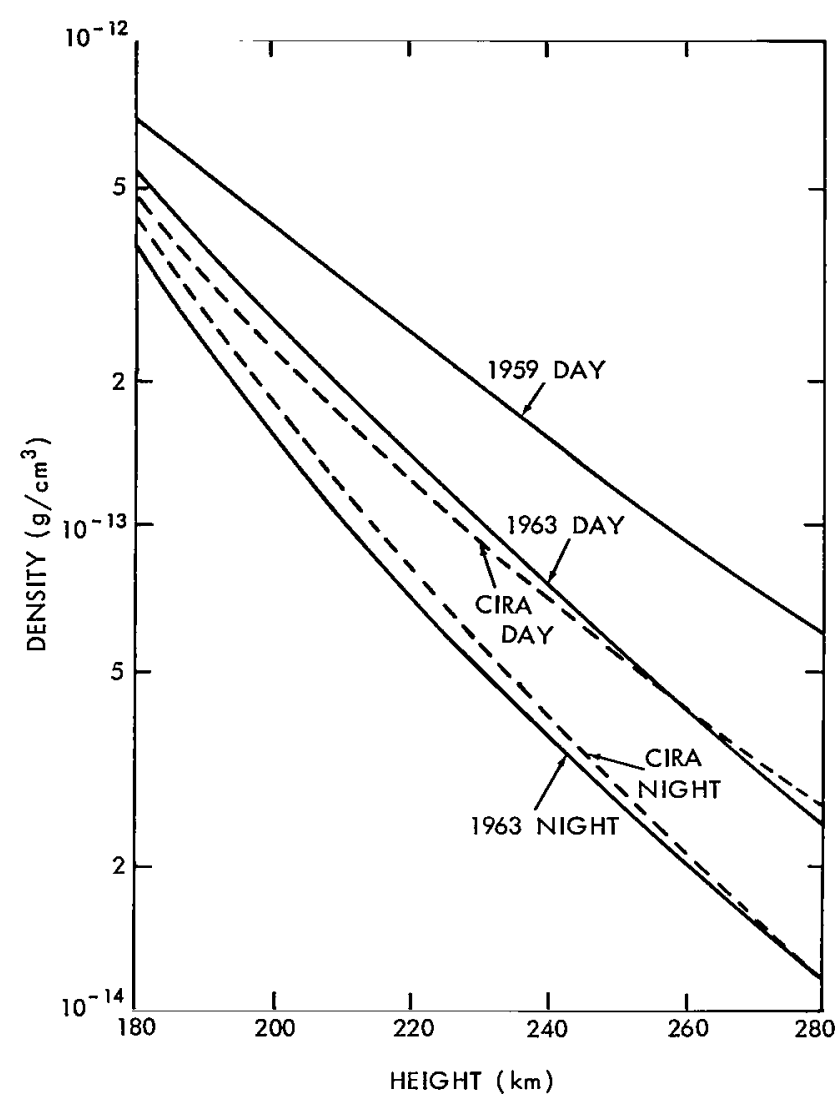

Figure 1-Diurnal variation of the density in the height range from 180 to $280 \mathrm{~km}$ for the year 1963 as determined by King-Hele and Quinn (Reference 3). Given are the daytime maximum and the nighttime minimum densities. They are compared with the corresponding CIRA Model 2 $(\bar{F}=75)$ for 1400 and 0400 hours local time. In order to indicate the variation during the solar cycle, the observational daytime maximum densities for 1959 are also given.

cycle needs improvement. Unfortunately quantitative conclusions cannot be reached at present. Observational evidence on the correct temperature profile in the lower thermosphere and a highly accurate knowledge of the chemical composition is urgently needed. Variations of the temperature at $120 \mathrm{~km}$ over an eleven-year cycle with a range of $50^{\circ} \mathrm{K}$ seem to be compatible with the available observational evidence. Also variations of the number densities at $120 \mathrm{~km}$ by as much as 30 per cent would be easily permissible.

The temperature measurements from cloud release experiments by Blamont (Reference 10) during the years 1960 to 1964 are compatible with a time-independent temperature at $120 \mathrm{~km}$ during that time interval. But this still allows a temperature variation of the order of $50^{\circ} \mathrm{K}$ during the 


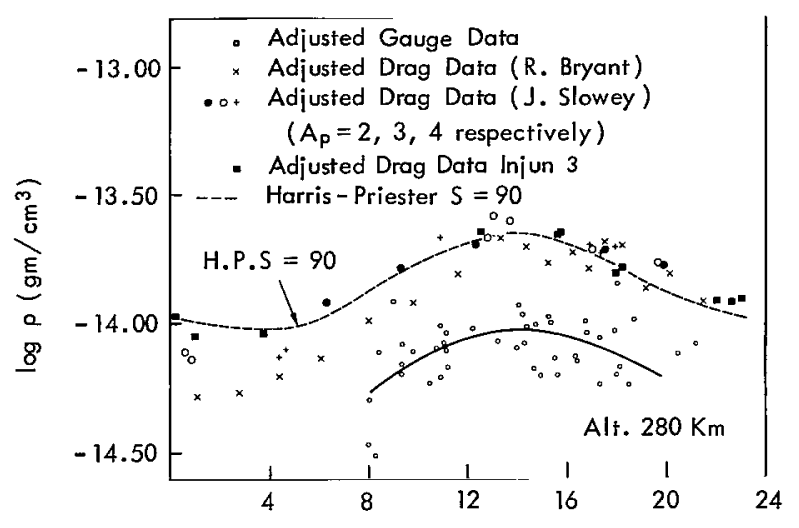

Figure 3-Comparison between gauge-measured densities and drag data, plotted as a function of local time. The gauge data are from an altitude range from 250 to 300 $\mathrm{km}$ and individually adjusted to $A_{p}=2$ (see text). The drag data are selected for geomagnetically quief conditions or adjusted to $A_{p}=2$. All data are normalized to a height of $280 \mathrm{~km}$ above sea level.

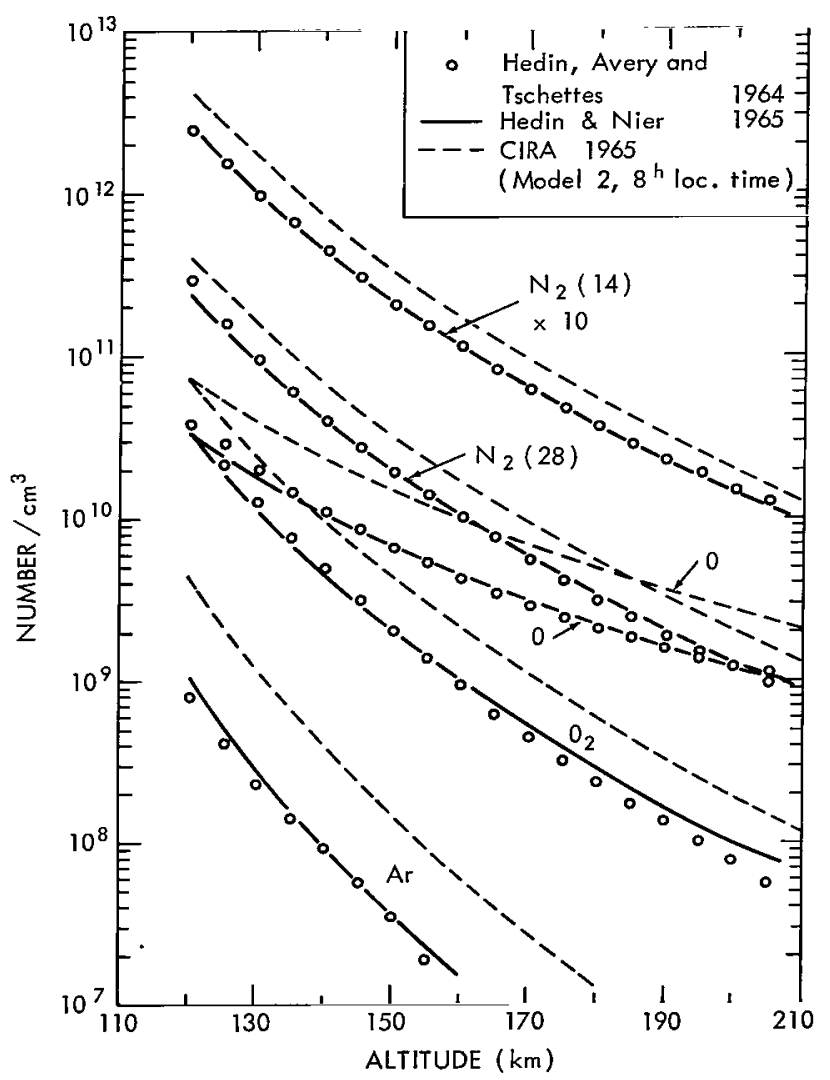

entire solar cycle. A series of rocket shots for measuring chemical compositions, temperatures, and densities over an entire solar cycle is urgently needed.

A curious discrepancy has been found between the recent direct measurements of atmospheric densities (total densities from pressure gauges and number densities from mass spectrometer measurements on board Explorer 17 and on rocket launchings) and the satellite drag measurements. This discrepancy amounts generally to a factor of about two in the sense that all drag derived values are larger than the directly measured values. This is illustrated in Figures 3 to 6 . Here, for convenience, the comparison is partly made with the CIRA or the Harris-Priester models instead of the primary drag data. One should recall that the models are representative of the densities derived from drag measurements exclusively, since direct measurements were not available in sufficient numbers at the time when those models were constructed (1962 and 1964).

Figure 3 provides a comparison of the gaugemeasured densities from Explorer 17 (Reference 11) and the drag-determined densities from the satellite Injun 3 (Reference 12) and Explorer 17 (References 5 and 13). The gauge data are from the altitude range of 256 to $300 \mathrm{~km}$, normalized to a height of $280 \mathrm{~km}$ by using the Harris-Priester model $\mathrm{S}=90$ as a differential altitude transformer. The Injun $3 \quad\left(\beta_{\tau} 2\right)$ data were selected for geomagnetically quiet conditions whenever $A_{p} \leq 2$.

Figure 4-Number densities of $\mathrm{N}_{2}, \mathrm{O}, \mathrm{O}_{2}$ and $\mathrm{A}$ from rocket-borne mass spectrometer measurements of June 6, 1963,0730 MST (Reference 15) are compared with the corresponding CIRA Model 2 for 0800 hours local time. The higher densities in the model are necessary in order to reproduce the drag-determined densities above 200 $\mathrm{km}$. 


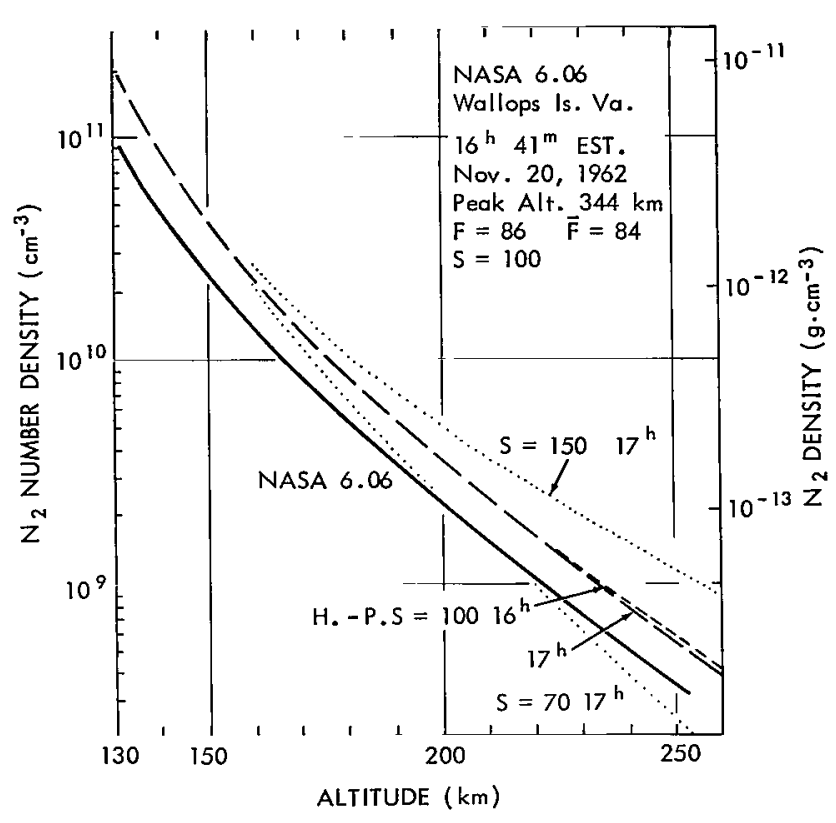

Figure 5-Number densities of $\mathrm{N}_{2}$ for November 20, 1962 (Reference 16) compared with the appropriate Harris-Priester model $S=100$ for 1700 hours local time. In order to demonstrate the solar cycle effect, the corresponding density curves for very low solar activity (model parameter $S=70$ ) and for average solar activity (average of the 11 -year cycle $)(S=150)$ are also given.

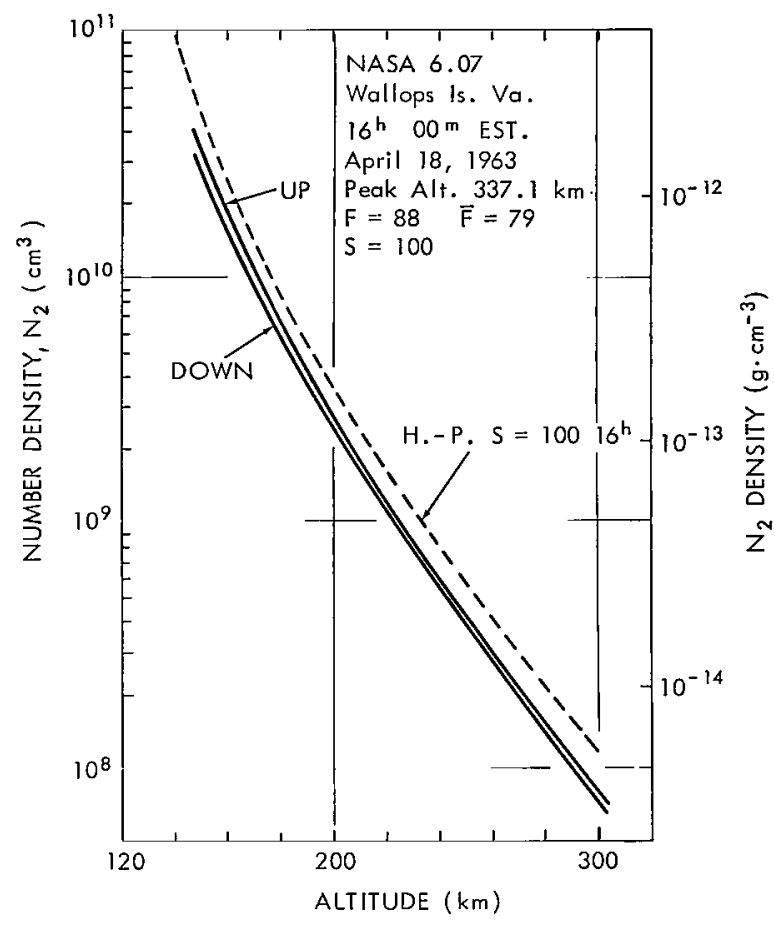

Figure 6-Number densities of $\mathrm{N}_{2}$ from rocket-borne mass spectrometer measurements of April 18, 1963 (Reference 16) are compared with the $\mathrm{N}_{2}$ values of the appropriate Harris-Priester model $\mathrm{S}=100$ for 1600 hours local time.

Slowey's Explorer 17 data were selected for $A_{p}=2,3$ or 4 . All other data were adjusted to $A_{p}=2$ by using the empirical relation derived by Newton, Horowitz and Priester (Reference 11).

The drag data and the corresponding Harris-Priester model densities are systematically higher than the gauge densities by a factor of two. This difference is greater than the combined uncertainties of both measurement techniques.

Figure 4 compares the number densities of $\mathrm{N}_{2}, \mathrm{O}, \mathrm{O}_{2}$ and $\mathrm{A}$ obtained from mass spectrometer measurements by Hedin, Avery, and Tschetter (Reference 14), Hedin and Nier (Reference 15) (from an Aerobee flight launched at 0730 MST, 6 June 1963 at White Sands, New Mexico, carrying a magnetic mass spectrometer) with the appropriate CIRA Model $2(\bar{F}=75)$ for 0800 hours local time. The 5-month average of the solar $10.7 \mathrm{~cm}$ flux for June 1963 is $\overline{\mathrm{F}}=81.4$, sufficiently close to the model parameter used. The figure gives the direct mass spectrometer results (circles) and the calculated values (solid line), derived under the assumption of diffusive equilibrium from the temperature profile, which was obtained as a by-product from an analysis of the effect of the rocket rotation on the measured densities. The calculated 
number densities were normalized such as to yield the observed values at $150 \mathrm{~km}$. The $\mathrm{N}_{2}$ data were obtained from the mass 28 and also from the mass 14 peak. In the figure the latter values are multiplied by 10 for clarity.

The measured number densities for $\mathrm{O}$ and $\mathrm{O}_{2}$ are lower by a factor of about two than those in the CIRA model. The model values are required to represent the satellite drag data above $200 \mathrm{~km}$. For $\mathrm{N}_{2}$ the factor is about 1.7. With regard to the temperature profile there is, however, good agreement between the data and the model. This can easily be seen from the fact that the curves are sufficiently parallel.

A similar discrepancy between observed and model number densities exists in the $\mathrm{N}_{2}$ data obtained from NASA 6.06 and 6.07 launchings from Wallops Island, Virginia, on 20 November 1962 and 18 April 1963 (Reference 16, Figures 5 and 6). The solar activity parameter corresponding to these dates are $\bar{F}=84$ and 81 (5-month averages). They are closely identical to the June 1963 value. Here the data are compared with the appropriate models of Harris and Priester (References 7 and 17) with a model parameter $S=100$ corresponding to the given solar activity parameter. The model values are too large by a factor of about 1.5 to 1.7. Again there is good agreement for the temperature profiles. A comparison with the new CIRA models instead of the Harris-Priester models would reveal only a small discrepancy at the lower heights, since the boundary values for the new CIRA models were adjusted as closely as possible to these mass spectrometer results.

There is no explanation offered yet for the discrepancy between the drag data and the direct measurements. The several independent calibrations of the pressure gauges and also of the mass spectrometers seem to rule out a calibration error as large as a factor of two. If, however, the drag data are the ones which are to be improved, it would require an additional drag force which is equal to the aerodynamical drag. It does not seem to be possible to have an effective drag coefficient of about 4 instead of the value 2.2 which is usually taken in the 200 to $500 \mathrm{~km}$ range. Recently a careful reinvestigation of the drag coefficients has been undertaken by Cook (Reference 18). His findings are that the value of 2.2 should be correct within a \pm 10 percent limit in the altitude range from 200 to $500 \mathrm{~km}$. On the other hand, a reduction of the drag-determined densities would immediately remove all the discrepancies and also would ease the high requirements on the absolute amount of heat available from the solar EUV radiation.

\section{THE 27-DAY VARIATION, THE SOLAR CYCLE EFFECT, AND THE EFFECT OF GEOMAGNETIC ACTIVITY}

The first effect which was found in the drag data was a variation with a period of approximately 27 days (Reference 19 ). These variations closely parallel the solar activity as measured in the decimeter flux (References 20 and 21).

It was, of course, evident from the beginning that the decimeter flux was only an index for the real heat source. The real source is obviously - at least to a large extent - the solar extreme 
ultraviolet radiation essentially below $911 \mathrm{~A}$. About 50 percent of the energy between 100 and $900 \mathrm{~A}$ is, according to Hinteregger, Hall, and Schmidtke (Reference 22) contained in the emission lines; the remaining 50 percent is in the continuum.

From the correlation between density and decimeter flux, it was possible to predict that the EUV flux undergoes distinct variations in accordance with the decimeter flux. The correlation further implies that an important part of the EUV flux originates in the coronal condensations, since the slowly varying component of the decimeter flux comes from these areas of enhanced electron densities and temperatures in the solar corona. The close parallel of the He II $304 \mathrm{~A}$ line and several other lines in the wavelength range between 50 and $400 \mathrm{~A}$ with the $10.7 \mathrm{~cm}$ flux has been proved by the measurements with OSO I in March and April 1962 (Reference 23).

Despite the fact that the amplitudes of the 27-day variations in the density- and 10.7-centimeter flux curve match each other, it is evident that the general long-term trend in the thermospheric density curve is about twice as steep as in the flux curve. The long-term trend is the so-called solar cycle effect. A more detailed analysis of the different behavior of the 27-day variation and the long-term variation, which is believed to exhibit an eleven-year period, was carried out by Jacchia (Reference 24), Paetzold (Reference 25), Roemer (Reference 26) and Harris and Priester (Reference 7). Roemer showed that the best way to describe the phenomenon is to use a five-month average of the solar $10.7 \mathrm{~cm}$ flux, $\bar{F}$, as a solar cycle index and the daily flux values $F$ for the 27day variation. Thus the nighttime minimum temperature of the exosphere can be calculated from $\bar{F}$ and $F$ in units of $10^{-22} \mathrm{~W} / \mathrm{m}^{2}(\mathrm{c} / \mathrm{s})$ :

$$
\begin{aligned}
\mathrm{T}_{04} & =3.40 \overline{\mathrm{F}}+460+1.9(\mathrm{~F}-\overline{\mathrm{F}}) & {\left[{ }^{\circ} \mathrm{K}\right] } \\
& =1.5 \overline{\mathrm{F}}+1.9 \mathrm{~F}+460 . & {\left[{ }^{\circ} \mathrm{K}\right] }
\end{aligned}
$$

These data represent the new CIRA tables. If one takes the Harris-Priester models as improved by Roemer, one obtains a very similar expression:

$$
\mathrm{T}_{04}=3.46 \overline{\mathrm{F}}+465+1.9(\mathrm{~F}-\overline{\mathrm{F}}) .
$$

Jacchia's static diffusion models (1964) yield, for the exospheric nighttime minimum temperature:

$$
\mathrm{T}_{4}=3.60 \overline{\mathrm{F}}+418+1.8(\mathrm{~F}-\overline{\mathrm{F}}) .
$$

The differences between the formulas are negligible. They remain essentially smaller than $25^{\circ} \mathrm{K}$ for the whole possible range of $\bar{F}$.

The formulas can be interpreted as follows: About 50 percent of the variable heat source parallels the daily decimeter flux. That means that the radiation which constitutes this part of the heat source originates in the coronal condensations. The remaining 50 per cent undergo a longterm variation but do not fluctuate within intervals of a few days. The latter displays the 11-year period in the structure of the solar corona. 
Some caution should be exercized with regard to the numerical values of the percentages, since they depend somewhat on the particular choice of the solar activity parameter. Since, however, OSO I proved the close proportionality between the EUV flux in the spectral lines and the $10.7 \mathrm{~cm}$ flux, we feel even more confident about the extreme usefulness of the solar decimeter radiation until we have a continuous surveillance of the EUV flux from future satellites. Then we will be able to replace the auxiliary activity parameter by the directly measured EUV fluxes.

It is tempting to suggest which parts of the solar spectrum are to be identified with the different contributors to the heat source. At the present time these suggestions are, of course, highly speculative, and are also apt to oversimplify the situation. The part which parallels the 27-day variation might essentially consist of the lines in the EUV range according to the evidence from the OSO I measurements. In this context it is also interesting to compare the results from a theoretical investigation by Suemoto and Moriyama (Reference 27). The part with the long-term variation might be supposed to consist mostly of the EUV continuum. Direct measurements of the EUV spectrum over a period of an 11-year solar cycle will show whether this simplified picture is essentially correct, in the sense that the emission lines show a stronger variability with the daily changes of solar activity than the underlying continuum.

Since 1959 several investigations have been undertaken in order to find out whether there is a delay (phase shift) between the variations in the solar EUV flux (or its indicator, the decimeter flux) on one hand, and the response of the thermosphere, i.e., the change of density and temperature, on the other hand. How large is the delay and how can it be interpreted?

The situation is still somewhat obscure. The first finding on Sputnik $2(1959 \beta 1)$ seemed to show a hint for a delay of about 2 days. Therefore, in 1959 Priester and Martin investigated this problem on the basis of the statistical material then available. These data were essentially from $1958 \beta 2$ (Vanguard 1), $1957 \beta$ and $1958 \delta 2$ (Sputnik 2 and 3) and $1958 \alpha$ (Explorer 1). The Vanguard 1 data are the dominant ones in the statistics. The perigee height of this satellite is about $650 \mathrm{~km}$. Priester and Martin (Reference 2) presented their results from Vanguard 1 in a histogram of the individually observed delay times. In order to construct the histogram, the following data had been used: the times of maxima and minima in the density and in the solar $20 \mathrm{~cm}$ flux and the centers of adjacent "half-power" points in both curves. The result was a delay of $0.5 \pm 0.5$ days. The scatter of the data representing a Gaussian distribution with a 1/e halfwidth of 3 days is due to the rather poor time resolution of the satellite data at that time (2.5 days). This is superposed to the $20 \mathrm{~cm}$ flux data with a one-day resolution. This combines to about 3 days.

Then, in 1963 MacDonald analyzed the time delay from the drag data of the balloon satellites Explorer $9(1963 \delta 1)$ and Echo $1(1961 ، 1)$. He found a statistically significant delay of 56 hours. Also a further investigation using the more recent and very accurate data of Explorer 9 again revealed a delay of slightly more than two days (Reference 28). He concluded from this that the 27-day variation results essentially from fluctuations in the solar wind. This conclusion, however, seems to be premature, since there are other explanations possible. 
Bourdeau, Chandra and Neupert (Reference 8) have recently investigated the time correlation between the thermospheric temperature as revealed by Explorer 9 and the OSO measurements of the EUV from March until May 1962. There are only two maxima and two minima. The statistics with four data are, of course, very poor (Figure 7). Our figure has been adapted from their paper. It shows a comparison between the flux in the EUV lines (integrated flux) as measured by OSO 1 and the thermospheric temperature, $\mathrm{T}$, from Explorer 9 (Reference 29) in the second line. Then the $10.7 \mathrm{~cm}$ flux follows. At the bottom the geomagnetic activity is given by $\Sigma \mathrm{K}_{\mathrm{p}}$.

With regard to the atmospheric temperatures derived from Explorer 9 it should be noted that the perigee of that satellite passed through the atmospheric bulge but remained close to the bulge center during March to May 1962. The bend-over of the dotted line connecting the Explorer 9 temperatures reflects the passage through the bulge.

The delay between the EUV flux and the temperature is $+2,+1,+2.5$ and -1 days. This might be summarized as a delay of the order of one day. It surely needs more observational evidence before conclusions can be made. A delay time of the order of one day within the 27-day variation can be attributed to the reaction time of the thermosphere. From a theoretical investigation of this effect there is some preliminary evidence that the temperature at $120 \mathrm{~km}$ undergoes a 27 -day variation with an amplitude of the order of $20^{\circ} \mathrm{K}$.

For years of very low solar activity $(1963,1964)$, the 27 -day variation is masked so highly by the geomagnetic activity effect, that a statistics of the phase shift is not feasible anymore. The geomagnetic activity effect, is a correlation between the geomagnetic index $\left(\mathrm{K}_{\mathrm{p}}\right.$ or $\left.\mathrm{A}_{\mathrm{p}}\right)$ and the density variations in the upper thermosphere. It was discovered by Jacchia in 1959 . During the years with rather high solar activity this effect can be distinguished clearly only when a large magnetic storm occurs. The situation is reversed for the years of low solar activity, when the 27-day variation disappears in the stronger variations which are correlated with geomagnetic activity.
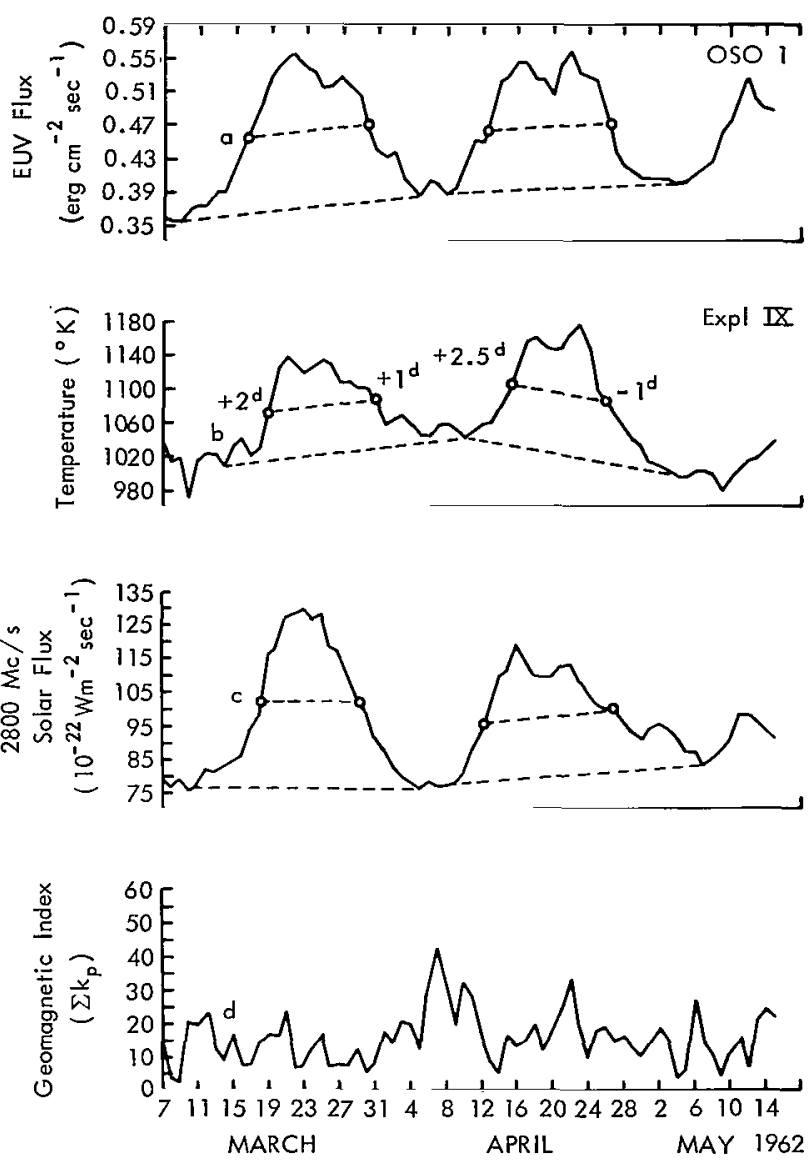

Figure 7-Comparison of the solar EUV flux from OSO 1 and the atmospheric temperature, derived from Explorer 9. Further, the solar $10.7 \mathrm{~cm}$ flux and the geomagnetic index $\Sigma K_{p}$ is given. (Adapted from Bourdeau, Chandra and Neupert (Reference 8 ). 
The superposition of the diurnal variation, the geomagnetic activity effect, and the 27-day variation is nicely displayed in the densities derived from Injun 3 (Figure 8) and from Explorer 17 (Figure 9). The data are plotted versus local time. Since the perigees move retrograde in local time, the dates (given on the top) increase toward the left side.

Figure 8 shows the density variations at an altitude of $250 \mathrm{~km}$ above sea level as a function of local time, $t$, as determined from accelerations of the satellite Injun 3 by Jacchia and Slowey (Reference 12) from December 15, 1962 through June 29, 1963. During this time the geographic latitude of the perigee covers the range from $+70^{\circ}$ to $-60^{\circ}$ as indicated by the numbers on the density curve. The solid and the dotted curve represent the Harris-Priester models for model parameters $S=90$ and $S=100$, respectively. The histograms in the upper part give the daily geomagnetic indices, $A_{p}$, and the solar $10.7 \mathrm{~cm}$ flux, $F$. At the top the dates of observations are given in the usual scale and in modified Julian dates (MJD). The black dots represent the densities during geomagnetically quiet days $\left(A_{p} \leq 2\right)$.

No pronounced and unequivocal dependence of density on latitude can be seen, but density variations correlated even with small geomagnetic disturbances show up clearly. It seems that

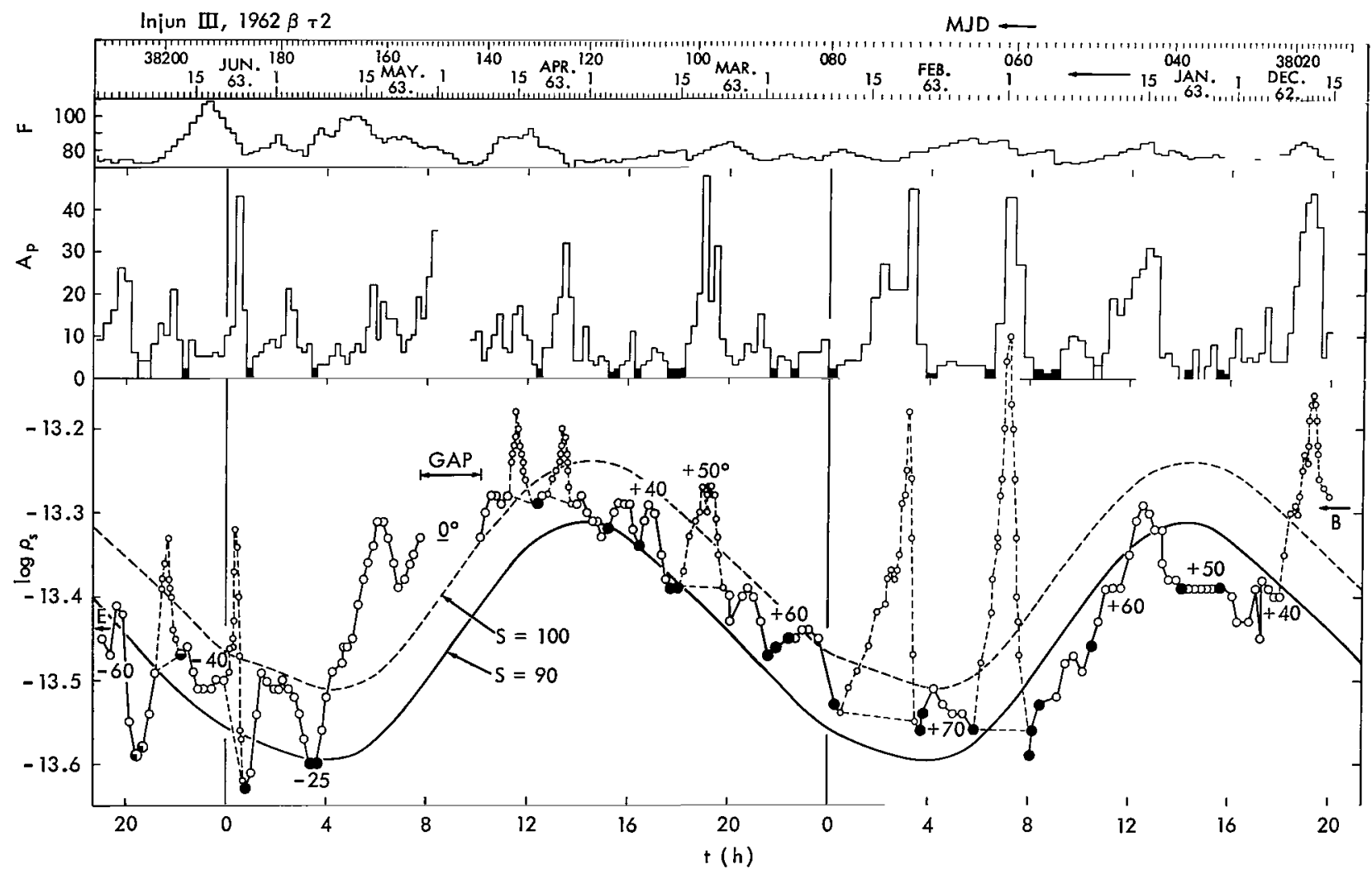

Figure 8-Densities at a height of $250 \mathrm{~km}$ above sea level derived from Injun 3 by Jacchia and Slowey for the time interval from December 15, 1962 through June 1963. The data are plotted as a function of local time of the perigee. The corresponding dates are given at the top, also as MJD (Modified Julian Dates). For comparison, the geomagnetic indices $A_{p}$ and the solar $10.7 \mathrm{~cm}$ flux $F$ are presented. The numbers on the densities indicate the geographic latitudes of the perigee. The curves represent the Harris-Priester models $S=90$ and $S=100$. 


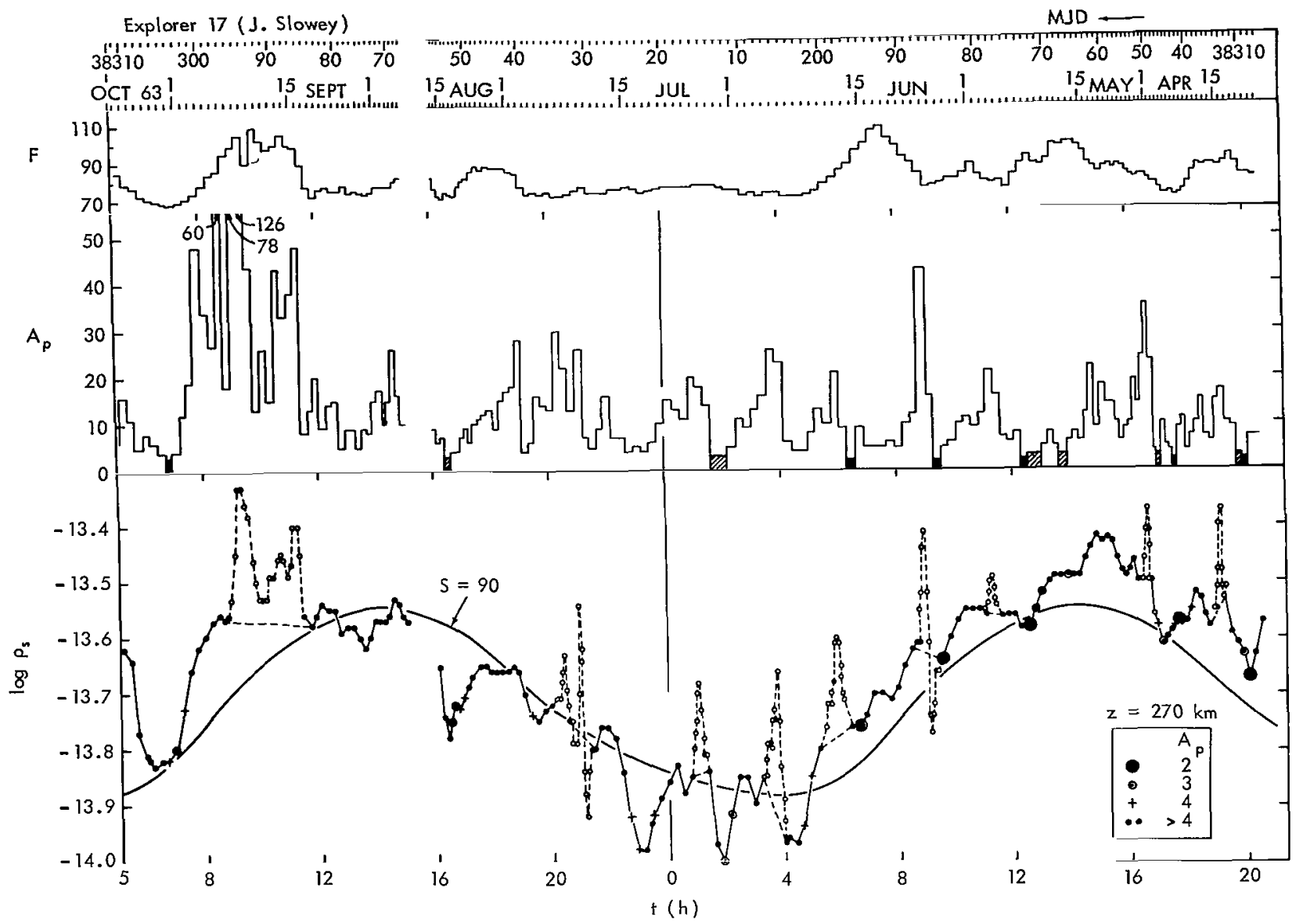

Figure 9-Densities at a height of $270 \mathrm{~km}$ derived from Explorer 17 by Slowey (Reference 5) for the time interval from April 8 to October 9, 1963. The data are compared with geomagnetic activity $\left(A_{p}\right)$ and solar $10.7 \mathrm{~cm}$ flux $F$. The representation corresponds to Figure 8 .

the reaction of the atmosphere to disturbances is greater at night and early morning than during daytime, in agreement with previous findings on atmospheric variations correlated with the 27day variation of the solar $10.7 \mathrm{~cm}$ flux (Reference 26). Furthermore, there is an outstanding difference between the reaction of the atmosphere in and outside the auroral zone during geomagnetic storms as pointed out by Jacchia and Slowey. Storm-time density variations up to a factor of 3 can be seen while the satellite's perigee was at a latitude of $+70^{\circ}$.

The quiet-day diurnal density variation has an amplitude of a factor of 1.9, in good agreement with the appropriate theoretical model of Harris and Priester (Reference 7). As we pointed out already, the observed diurnal amplitude at $250 \mathrm{~km}$ for low solar activity is considerably larger than for times of high solar activity. The average solar $10.7 \mathrm{~cm}$ flux from December 1962 through June 1963 was $\bar{F}=81$ in the usual units. This implies a model parameter of about $S=100$ according to Harris and Priester, (Reference 17). This model fits the observed densities for slightly disturbed days $\left(4<A_{p}<10\right)$. 
For the extreme quiet days $\left(A_{p} \leq 2\right)$ (black dots), a best fit is obtained with a model $S=90$. The high precision in the density determinations requires one to account for the mean level of geomagnetic disturbance in addition to the average solar $10.7 \mathrm{~cm}$ flux when comparisons are made with the theoretical models.

Since we approach the solar minimum, the 27-day variations in density correlated with the daily solar $10.7 \mathrm{~cm}$ flux values can hardly be recognized anymore. The variations in the $10.7 \mathrm{~cm}$ flux normally cease completely during the solar minimum.

Figure 9 presents the densities at a height of $270 \mathrm{~km}$ for the time from 8 April 1963 to 9 October 1963 as determined by Slowey (Reference 5) from the drag on the Explorer 17 satellite. The graph presents the same quantities as Figure 8. The abscissa is the local time of the perigee.

Again the strong reaction of the density to increases in geomagnetic activity is very conspicuous. The deviation of the observed densities from the model values in late June and early July can be attributed to the well-known minimum of the semi-annual effect. This effect is described in Jacchia's review (Reference 1) and by Paetzold (Reference 30). The cause of this effect is not yet understood. It might be related to an energy source from the solar wind-a permanent component of the heat source which correlates with geomagnetic activity-or it might be caused by a global horizontal convective pattern.

The more recent statistics of the geomagnetic activity effect in the thermosphere revealed a very interesting feature (References 11 and 31). From the early statistics when only pronounced magnetic storms showed their effect in the thermospheric density and temperature, Jacchia found that the increase of the temperature is proportional to the geomagnetic index $A_{p}$ :

$$
\Delta \mathrm{T} \sim \mathrm{A}_{\mathrm{p}}
$$

Now it became apparent that for $A_{p}$ up to even as high as $A_{p}=100$, a logarithmic approximation is a better representation:

$$
\Delta \mathrm{T} \sim \log \mathrm{A}_{\mathrm{p}}
$$

Jacchia and Slowey give an analytic expression which combines the two empirical relations. For instance, from the old formula it was expected that an increase in $A_{p}$ from 2 to 10 would be accompanied by an increase of $\Delta \mathrm{T}=8^{\circ} \mathrm{K}$ in the thermosphere. Now it was found that the increase is $\Delta \mathrm{T}=80^{\circ} \mathrm{K}$, ten times as much as anticipated. It must be noted that between $A_{p}=1$ and 0 , the simple logarithmic approximation necessarily breaks down, since it would yield an infinite change in temperature. One might, however, wonder how large the contribution from this heat source to the total heating really is for extremely quiet geomagnetic conditions. The unsolved question is whether this heat source vanishes for $A_{p}=0$ or whether a permanent "quiet" component exists.

The strong relation of the atmosphere to variations in geomagnetic activity suggests an investigation of the delay time between the atmospheric reaction and the maxima of the magnetic storms in a similar fashion as had been carried out for the 27-day variation. In Figure 10 the results are plotted using again the local time as the ordinate of the graph. The data from Explorer 
9 were taken from the analysis of Jacchia and Slowey (Reference 29). For the analysis of Explorer 17 and Injun 3 the densities determined by Slowey (Reference 5) and by Jacchia and Slowey (Reference 12) were used. The three-hourly geomagnetic indices were adjusted to the time resolution of the satellite data. The phase shifts were then determined from a comparison of the curves of the density variation and the geomagnetic activity variation. The observed delay times are $6 \pm 3$ (m.e.) hours. There is no conspicuous dependence of the delay time on local time. Thus the atmospheric reaction occurs apparently worldwide at the same time on the day- and night-side of the earth. The statistics are,

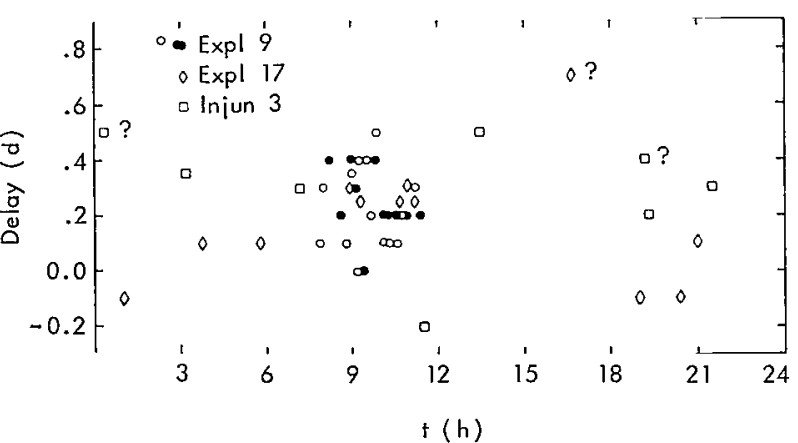

Figure 10-Phase shift between the storm time variations of geomagnetic activity and the related density variations in the thermosphere for 45 geomagnetic storms plotted as a function of local time of the satellites' perigee. On the average the density increase is 6 hours \pm 3 (m.e.) hours behind the geomagnetic increase. The ordinate scale is given in parts of a day. however, still poor and the conclusion might be subject to improvement when more data for afternoon and night times become available. Unfortunately it was not yet possible to investigate any dependence on latitude.

It can be hoped that the huge amount of data from satellite drag measurements and from direct experiments on board satellites and rockets will greatly contribute to a better understanding of the physics of the thermosphere.

\section{ACKNOWLEDGMENTS}

I gladly acknowledge the hospitality of the Institute for Space Studies and extend my thanks to Dr. Robert Jastrow, the director of the Institute, and to the staff members for their stimulus.

I am grateful to the National Academy of Sciences - National Research Council for a Senior Research Associateship.

(Manuscript received June 25, 1965)

\section{REFERENCES}

1. Jacchia, L. G., "Atmospheric Structure and its Variations at Heights above $200 \mathrm{Km}$ ", Amsterdam: North-Holland Publishing Company CIRA 1965 (see also Ref. 9).

2. Priester, W., Martin, H. A., and Kramp, K., "Diurnal and Seasonal Density Variations in the Upper Atmosphere," Nature, 188(4746):202-204, October 15, 1960. 
3. King-Hele, D. G., and Quinn, E., "Air Density at Heights from $150-300 \mathrm{Km}$ in the Years 1962-4," Roy. Aircraft Est. Tech. Rept. 64097, 1964.

4. Marov, M. Y., "Density of the Upper Atmosphere from the Drag of Soviet Satellites," in: Space Research V; Proceedings of the International Space Science Symposium, Florence, May 12-16, 1964, ed. by D. G. King-Hele, R. Muller, and G. Righini, Amsterdam: NorthHolland Publishing Co.; New York: Interscience Publishers, Inc., 1965, pp. 1140-1149.

5. Slowey, J., "Atmospheric Densities and Temperatures from the Drag Analysis of the Explorer 17 Satellite," Cambridge, Massachusetts: Smithsonian Astrophysical Observatory Special Report 157; NASA CR-58032, July 1, 1964.

6. Martin, H. A., Neveling, W., Priester, W., and Roemer, M., "Model of the Upper Atmosphere from 130 through $1600 \mathrm{Km}$, Derived from Satellite Orbits, "in: Space Research II, ed. by H. C. van de Hulst, C. de Jager, and A. F. Moore, Amsterdam: North-Holland Publishing Co.; New York: Interscience Publishers, Inc., 1961, pp. 2902-917.

7. Harris, I., and Priester, W., "Theoretical Models for the Solar-Cycle Variation of the Upper Atmosphere," NASA Technical Note D-1444, August 1962; also published in J. Geophys. Res. 67(12):4585-4592, November 1962.

8. Bourdeau, R. E., Chandra, S., and Neupert, W. M., "Time Correlation of Extreme Ultraviolet Radiation and Thermospheric Temperatures," J. Geophys. Res. 69(21):4531-4536, November 1964.

9. "CIRA 1965, COSPAR International Reference Atmosphere," 2nd edition, Working Group IV of COSPAR, 1965, Amsterdam: North-Holland Publishing Company, 1965.

10. Blamont, J. E. and Chanin-Lory, M. L., "Temperature Measurements in the Ionosphere from 100 to $400 \mathrm{~km}$ between 1960 and 1964," in Space Research V, Amsterdam: North-Holland Publishing Co., 1965, p. 1137-1139.

11. Newton, G. P., Horowitz, R., and Priester, W., "Atmospheric Density and Temperature Variations from the Explorer XVII Satellite and a Further Comparison with Satellite Drag," GSFC Document X-651-65-33, January, 1965, and Planet. Space Sci., 13(7):599-616, July 1965.

12. Jacchia, L. G., and Slowey, J., "Atmospheric Heating in the Auroral Zones: A Preliminary Analysis of the Atmospheric Drag of Injun III Satellite," Cambridge, Massachusetts: Smithsonian Astrophysical Observatory Special Report Number 136; NASA CR-52456, September 17, 1963.

13. Bryant, R., "Densities Obtained from Drag on Explorer 17 Satellite," J. Geophys. Res. 69(7):1423-1425, April 1, 1964.

14. Hedin, A. E., Avery, C. P., and Tschetter, C. D., "An Analysis of Spin Modulation Effects on Data Obtained with a Rocket-Borne Mass Spectrometer," J. Geophys. Res. 69(21):4637-4648, November 1, 1964.

15. Hedin, A. E., and Nier, A. O., "Diffusive Separation in the Upper Atmosphere," J. Geophys. Res. 70(5):1273-1274, March 1, 1965. 
16. Spencer, N. W., Brace, L. H., Carignan, G. R., Teusch, D. R., and Niemann, H., "Electron and Molecular Nitrogen Temperature and Density in the Thermosphere," J. Geophys. Res. 70(11):2665-2698, June 1, 1965.

17. Harris, I., and Priester, W., "Relation between Theoretical and Observational Models of the Upper Atmosphere," J. Geophys. Res. 68(20):5891-5894, October 15, 1963.

18. Cook, G. E., "Satellite Drag Coefficients," Roy. Aircraft Est. Tech. Rept. 65005, 1965.

19. Jacchia, L. G., and Briggs, R. E., "Orbital Acceleration of Satellite 1958 B2," in: Optical Satellite Tracking Program; Satellite Data and Analyses, ed. by G. F. Schilling, Cambridge, Massachusetts: Smithsonian Astrophysical Observatory Special Report 18, October 14, 1958, pp. 9-12; also in Smithsonian Contributions to Astrophysics, 6:13-15, 1963.

20. Priester, W., and Martin, H. A., "Solare und Tageszeitliche Effekte in der Hochatmosphäre aus Beobachtungen kunstlicher Satelliten," Mitt. Univ.-Sternwarte Bonn No. 29, 1959.

21. Jacchia, L. G., "Two Atmospheric Effects in the Orbital Acceleration of Artificial Satellites," Nature, 183(4660):526-527, February 21, 1959.

22. Hinteregger, H. E., Hall, L. A., and Schmidtke, G., "Solar EUV Radiation and Neutral Particle Distribution in July 1963 Thermosphere," in: Space Research V; Proceedings of the International Space Science Symposium, 5th, Florence, May 12-16, 1964, ed. by D. G. King-Hele, P. Muller, and G. Righini, Amsterdam: North-Holland Publishing Co.; New York: Interscience Publishers, Inc., 1965, pp. 1175-1190.

23. Neupert, W. M., Behring, W. E., and Lindsay, J. C., "The Solar Spectrum from 50 A to 400 A," in: Space Research IV; Proceedings of the International Space Science Symposium, 4th, Warsaw, Poland, June 4-10, 1963, ed. by P. Miller, Amsterdam: North-Holland Publishing Co.; New York: Interscience Publishers, Inc., 1964, pp. 719-729.

24. Jacchia, L. G., "Electromagnetic and Corpuscular Heating of the Upper Atmosphere," in: Space Research III; Proceedings of the International Space Science Symposium, 3rd, Washington, D. C., May 2-8, 1962, ed. by W. Priester, Amsterdam: North-Holland Publishing Co.; New York: Interscience Publishers, Inc., 1963, pp 3-18.

25. Paetzold, H. K., "Solar Activity Effects in the Upper Atmosphere Deduced from Satellite Observations," in: Space Research III; Proceedings of the International Space Science Symposium, 3rd, Washington, D. C., May 2-8, 1962, ed. by W. Priester, 28-52, Amsterdam: North-Holland Publishing Co.; New York Interscience Publishers, 1963, pp. 28-52.

26. Roemer, M., "Die Dichte der Hochatmosphare und ihre Variationen während der Phase abklingender Sonnenaktivität 1958-1962," Veröfentlichungen der Universitäts-Sternwarte zu Bonn, Number 68:1-146, 1963.

27. Suemoto, Z., and Moriyama, F., "Interpretation of Solar Extreme Ultraviolet Spectra Observed with Rockets from a New Model of the Solar Chromosphere," in: Space Research III; Proceedings of the International Space Science Symposium, 3rd, Washington, D. C., May 2-8, 1962, ed. by W. Priester, Amsterdam: North-Holland Publishing Co.; New York: Interscience Publishers, Inc., 1963. 
28. MacDonald, G. J. F., "The Escape of Helium from the Earth's Atmosphere," Rev. Geophys. 1(3):305-349, August 1963.

29. Jacchia, L. G., and Slowey, J., "An Analysis of the Atmospheric Drag of the Explorer IX Satellite," in: Space Research IV; Proceedings of the International Space Science Symposium, 4th, Warsaw, Poland, June 4-10, 1963, ed. by P. Muller, Amsterdam: North-Holland Publishing Co.; New York: Interscience Publishers, Inc., 1964, pp. 257-270.

30. Paetzold, H. K., "New Results about the Annual and Semi-Annual Variation of the Upper Terrestrial Atmosphere," in: Space Research IV: Proceedings of the International Space Science Symposium, 4th, Warsaw, Poland, June 4-10, 1963, ed. by P. Muller: Amsterdam: North-Holland Publishing Co.; New York: Interscience Publishers, 1964, pp. 271-278.

31. Jacchia, L. G. and Slowey, J., "Temperature Variations in the Upper Atmosphere During Geomagnetically Quiet Intervals," J. Geophys. Res. 69(19):4145-4148, October 1, 1964. 
"The aeronautical and space activities of the United States shall be conducted so as to contribute... to the expansion of buman knowledge of phenomena in the atmosphere and space. The Administration shall provide for the widest practicable and appropriate dissemination of information concerning its activities and the results thereof."

-National Aeronautics and Space Act of 1958

\section{NASA SCIENTIFIC AND TECHNICAL PUBLICATIONS}

TECHNICAL REPORTS: Scientific and technical information considered important, complete, and a lasting contribution to existing knowledge.

TECHNICAL NOTES: Information less broad in scope but nevertheless of importance as a contribution to existing knowledge.

TECHNICAL MEMORANDUMS: Information receiving limited distribution because of preliminary data, security classification, or other reasons.

CONTRACTOR REPORTS: Technical information generated in connection with a NASA contract or grant and released under NASA auspices.

TECHNICAL TRANSLATIONS: Information published in a foreign language considered to merit NASA distribution in English.

TECHNICAL REPRINTS: Information derived from NASA activities and initially published in the form of journal articles.

SPECIAL PUBLICATIONS: Information derived from or of value to NASA activities but not necessarily reporting the results of individual NASA-programmed scientific efforts. Publications include conference proceedings, monographs, data compilations, handbooks, sourcebooks, and special bibliographies.

Defails on the availability of these publications may be obtained from:

SCIENTIFIC AND TECHNICAL INFORMATION DIVISION

NATIONAL AERONAUTICS AND SPACE ADMINISTRATION

Washington, D.C. 20546 